\title{
PROBING POTENTIALS OF DIGITAL AND PHYSICAL MODELLING IN CONSTRUCTION COURSES
}

\author{
MORA A. HANA, KHALID S. AL-HAGLA \& INGI ELCHERIF \\ Department of Architectural Engineering, Faculty of Engineering, Alexandria University, Egypt
}

\begin{abstract}
There are a variety of methods and tools used by educators to teach building construction to architecture students. These methods and tools aim to cover the many and complex skills and knowledge associated with this course. Modelling is a tool that is commonly being used during project-based learning within building construction courses. This research aims to: (1) Examine the potentials of digital and physical modelling as tools for project-based learning; (2) detect the relative ability between the two tools to enhance learning outcomes. The results of this research shall help educators make better decisions when choosing learning tools according to their educational goals. After reviewing the literature related to each tool, a comprehensive list for educational realms and learning outcomes related to building construction courses was developed. Based on this list, a questionnaire and investigative interviews were conducted with two groups, one of them had used digital modelling while the other had used physical modelling within two different projects. It was found that learning outcomes relate not only to the use of the tool itself, but also to the individual/ teamwork setting of the experience, in addition to the size and complexity of the project, and the diversity of its details, materials, and systems. The findings illustrate how these tools and settings can enhance learning outcomes.

Keywords: digital modelling, physical modelling, Revit, BIM, mock-up, design-build, building construction, project-based learning, architectural education.
\end{abstract}

\section{INTRODUCTION}

Building Construction courses are major courses in any architecture program. These courses are mainly concerned with technical documentation and specifications [1], [2]; construction materials and methods [1]-[3]; MEP (mechanical, electrical and plumbing) systems [1]-[3]; structural systems [1]-[3]; and construction management [1], [3]. Building construction courses are also related to environmental systems and integrated architectural solutions [1]-[3]. It also supports students' acquisition of skills that qualify them to work in this field [1]-[3].

Methods of teaching are varied in order to develop a cultural richness for the previously mentioned aspects of building construction. This variety also allows for flexibility in the development of the curriculum to respond to different demands and requirements [1], [2]. Common methods and techniques used in this context include structured and ill-structured researches; problem-based exercises; analysis for hypothetical or realistic cases; field trips; apprenticeships; and project work. Project-based learning is among the most popular experiential learning methods that are used in building construction courses. Digital and physical modelling are two of the most used tools that allow learning by doing. Schank [4] calls them as "doing devices".

Despite the large number of studies related to the use of digital and physical modelling in the framework of the architectural design studio, the number of these studies in the framework of the construction studio is much less. Some studies have reviewed these tools in terms of a specific topic such as "structure" [5] or "spatial understanding" [6] or "preferences and attitudes" toward the use of each of the two tools [7]. Other studies have considered a very limited number of learning outcomes [8], while some had only discussed the final model as the final outcome [9]. This research aims to examine the potentials of digital and physical modelling (as tools for project-based learning) for acquiring learning 
outcomes related to building construction courses. It also aims to detect the relative ability between the two tools to enhance learning outcomes.

After reviewing the literature and presenting a description for the studied cases, a wide-ranging list of educational realms and learning outcomes related to building construction was developed. This list helps to examine the potentials of each tool using a broad measure to explore possible unanticipated learning outcomes. A questionnaire and structured interviews were made with two groups of the same community, the same university, and the same semester. One of them used Revit (digital modelling tool), while the other used a scaled mock-up (physical modelling tool) during their projects.

\section{LITERATURE REVIEW}

\subsection{Project-based learning}

Project-based learning is an experiential learning approach that focuses on the application or integration of previously acquired knowledge through completing a project [10], [11]. It is a learner-driven activity where students are exposed to real-world problems that involve them in problem-solving, investigative activities, decision making or design in which they could learn relatively [12]. Project-based learning also have a positive impact on conceptual understanding and attitudes to learning [11]. During project work students must learn to take responsibility to complete the tasks and to engage in the give-and-take required for effective teamwork [12]. They need to have patience, be able to recognize patterns and observe things closely. Students also need skills to take measurements, use tools appropriately, record data accurately, and look for alternative explanations of data [12].

\subsection{Digital modelling}

Digital modelling includes computer-based simulations such as traditional digital 3D model, BIM model, virtual reality, augmented reality and digital twin. Building Information Modelling (BIM), which is the focus of this research, is an intelligent 3D model-based process that has emerged strongly in the market, and has been integrated into educational curricula by many educational institutions [13]. Revit and ArchiCAD are two of the most popular software in the field that support BIM.

BIM projects are related to elements and assemblies. They can also be used to analyse building's performance in terms of structural and environmental aspects [14], [15]. California State University stated that BIM had a role in learning construction details and material take-offs (MTO), while University of Florida have used BIM as a tool to learn the basic aspects of structural design [13]. The parametric modelling, intelligent object behaviour, and the clear visualizations enable deep learning and understanding of buildings [16], [17]. BIM projects enhances modelling skills for design and representation [17]. Montana State University have used BIM as a tool for 3D visualization to depict building systems integration and to achieve comprehensive design, it also has used it as a tool to generate construction documents [13]. Many other universities had praised BIM's potential to assist cross-disciplinary processes [13]. BIM projects also contributes to enhancing collaboration and teamwork skills [13], [17].

\subsection{Physical modelling}

Through physical modelling, students practice "Learning by building" [18] or "Learning by making" [19]. A mock-up is a scaled or full-sized model that is used for demonstrating and 
evaluating the functionality of a design [20]. Sometimes it's referred to as "design-build" as well [9], [21]. However, design-build is not limited to making mock-ups, it usually expresses doing projects that students design and implement in real-world context [22]. Material weight, scale, and cost are among the main challenges that students face while undertaking design-build projects [23], [24]. In order to reduce the impact of these challenges, scaled models are used, thus reducing the size of the cross-sections and materials. Also, much lighter materials could be used to represent heavier materials [24]. However, this may lead the student to a too scaled down modelling experience. Or it may restrict the type and scale of projects that are taken up [24]. The focus of this research will be on mock-ups that use real materials only.

Schwartz [21] presented a case study of two experiences, one of which was a full-scale mock-up for a wooden wall section, and the other was an amphitheatre. The results indicated that both experiences had a role in students' understanding of how to build with wood and understanding of building materials and assemblies. Some schools aim to enable students to explore materials and materiality through building projects [23]. In her framework of designbuild learning outcomes, Melcher [25] also confirmed the role of design-build in acquiring knowledge of construction materials, methods, and documentation. The results of the case study of Schwartz [21] indicated that learning by building could partially enhance proper selection of materials. Of course, these learning outcomes won't be valid if a mock-up does not include working with real materials and real assembling methods. Some schools aim to provide construction experience and larger vision of the profession through design-build experiences [23]. Learning by building helps to understand how a design document translates into a build project and vice versa [25]. It also enhances collaborative and teamwork skills [17], [23], [25]. Learning by building also enhances knowledge of how to work within practical limitations, ability to communicate with clients and contractors, ability to adapt to change and unexpected circumstances, and capacity to experiment and learn from mistakes [25]. It also contributes in the development of personal qualities such as confidence [25].

\section{CASE OF ALEXANDRIA UNIVERSITY}

The main construction course in the second year of the architecture program at Alexandria University consists of two main parts. The first part extends through the first semester, where students learn about complementary elements of a building (openings and stairs) and finishing materials. Students learn through lectures and research assignments. They also learn through studio-based problem-solving exercises, discussions and critiques. The second part extends through the second semester, were students are asked to apply the wide range of vocabulary and details they have learned through previous building construction courses into a project. The course content is formally presented in one-and-a-half-hour lecture per week, in addition to 3 hours in the studio. However, this time division may often overlap according to the teaching needs. Two case studies were chosen from the same community, the same university, and the same educational degree at the time of the studied experiences.

\subsection{The Revit project 2017}

In the second semester of the academic year 2016/2017, 106 of second-year students were asked to apply the concepts and details that they have previously acquired into a club house project. The project was previously designed by each student during the design course of the first semester. It was the first time that students were asked to use Revit during their studies. It was mainly used by students as a modelling tool and for material take-offs in a totally individual manner. Other BIM-related Revit capabilities, such as building energy 
and environmental performance, generative design, and work-sharing, have not been exploited during this course. It is worth mentioning that students had 4-6 mandatory practical sessions in the use of Revit before starting the project. Some of the deliveries were made manually first, then delivered using Revit later. Part of a sample for the project is shown in Fig. 1.

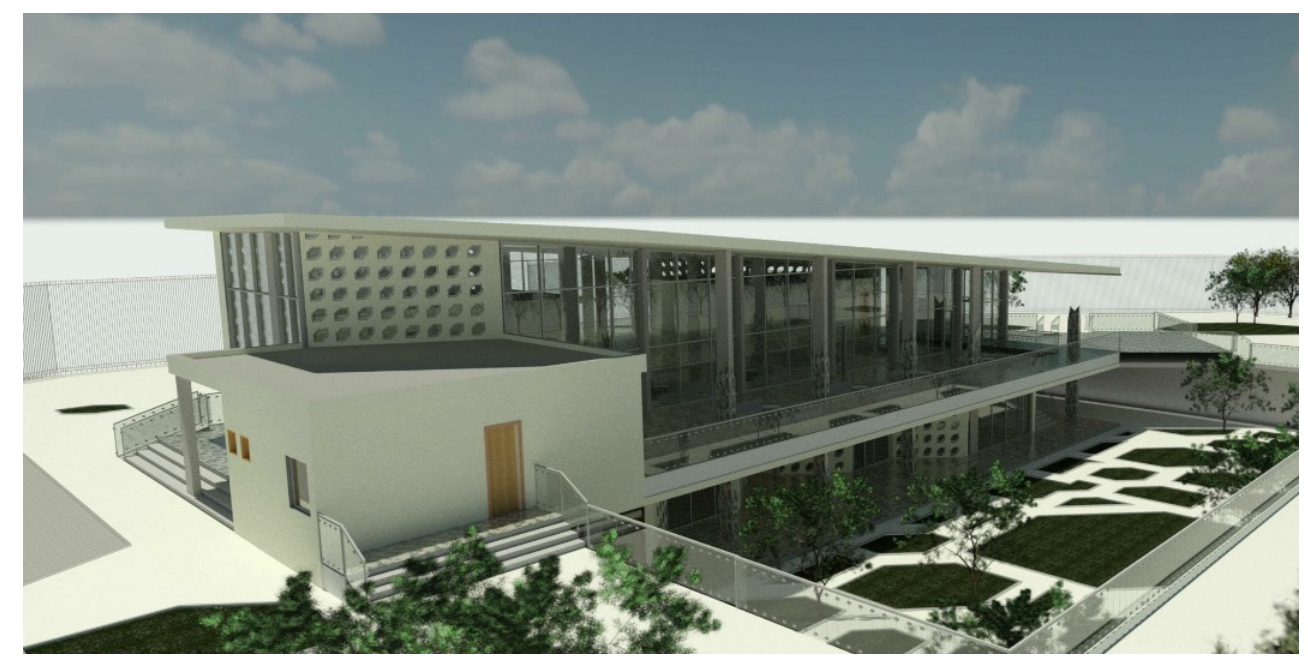

Figure 1: A sample for the club house Revit project done by a 2nd-year architecture student at Alexandria University in Spring 2017. (Copyright: Nessma Magued.)

\subsection{The 1:2 physical mock-up project 2016}

After finishing the first semester, faculty members noted that 2015/2016 second-year students deal with topics with a theoretical perception, and that their practical perception needed further reinforcement. They also wanted to develop collaboration and teamwork skills by having them work on parts of a project in a teamwork setting so that these parts are brought together to form a single integrated project. At the beginning of the second term, all 96 students were asked to be divided into 9 groups. Each group consisted of 9-12 students. They were given the architectural ground floor plan of a two-story residential villa. The parts of the project were assigned to each group: staircase and fixed window; structure and walls; window door; window and plank floor; mashrabiya and built-in bench; sliding door; solid core door; pressed door and parquet floor; and curved wall windows and plank floor. Students were free to choose the appropriate design and to assume any other data unless noted. The 1:2 Design-Build mock-up had to be identical to reality in terms of materials, details and installation methods as shown in Fig. 2. Students spent two weeks working on the design and the execution drawings and they spent a whole week in implementation. The working hours for the execution of this project were approximately from 8:30 am to 8:00 pm, for a period of 6 days, equivalent to 69 working hours. 

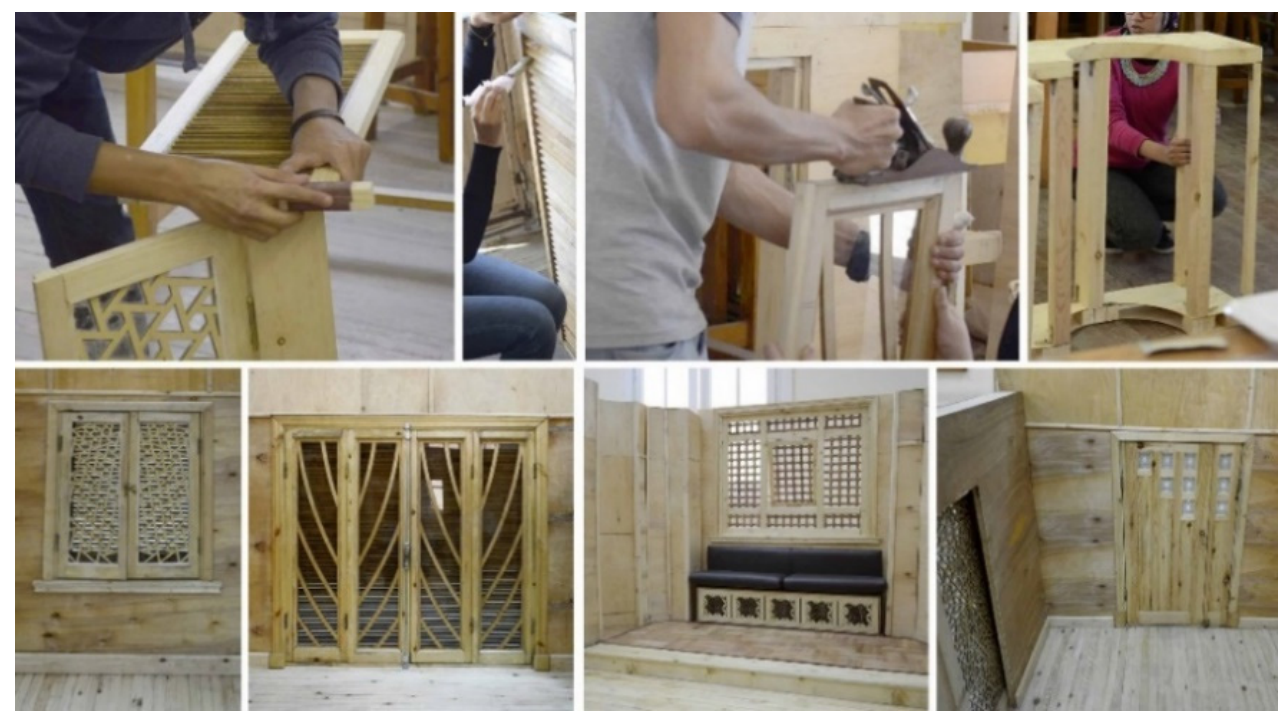

Figure 2: The 1:2 mock-up done by 2nd-year architecture students at Alexandria University in Spring 2016. (Copyright: Mahmoud Borhamy.)

\subsection{Measurement and instruments}

A wide-ranging list of learning outcomes was developed through reviewing, filtering and merging the student performance criteria of three organizations that grant accreditation to architecture schools around the world: NAAB, UIA, and RIBA. NAAB's index of learning outcomes according to educational realms was preserved. This indexing was chosen to reduce student distraction while answering the questionnaire and to facilitate the discussion. The list consists of 20 educational realms that are categorized into 4 groups: (1) educational realms related to building practices, technical skills, and knowledge; (2) educational realms related to integrated architectural solutions; (3) educational realms related to critical thinking, representation, and general skills; (4) and educational realms related to professional practice. Each educational realm consists of a number of learning outcomes. The total number of learning outcomes is 67.

A pilot questionnaire of 23 questions (see Table 1) based on the previously developed list was prepared in both English and Arabic languages to comply with the respondent's preference. The first three questions aimed to have an insight of the sample (gender, current work, their satisfaction of the used tool) while the remaining twenty were multiple checkboxes questions where respondents were to mark learning outcomes that they believe the studied tool (digital/physical modelling) had contributed in acquiring them. With a total of 67 checkboxes that students needed to read and understand, all pilot respondents (4 respondents) stated that the survey was complicated, long and boring. Accordingly, a 23-minute soundtrack was recorded by the researcher in which the same questionnaire was narrated and presented in a less formal way to facilitate understanding, while giving enough time for the respondent to answer the questionnaire. After testing this method with another 4 respondents, they indicated that they had no difficulty answering the questionnaire. 
The students' consensus on the acquired learning outcomes was used as an indicator of the potential of each tool in contributing to the acquisition of the studied learning outcomes. Fisher's exact text was conducted to look for statistical significance of consensus between both groups. Respondents were optionally requested to leave their phone number at the end of the questionnaire to conduct further investigation through a phone interview. Later, around 35 minutes phone interviews were made with 5 students from each group to discuss some of the results that were extracted from the questionnaire.

Table 1: A sample of a question from the questionnaire. (a) It illustrates the educational realm "Technical documentation" and the learning outcomes under it; (b) It also clarifies the corresponding codes in the references on which learning outcomes is based, but this part was not revealed to the respondents.

\begin{tabular}{|c|c|c|c|c|}
\hline \multicolumn{2}{|r|}{$\begin{array}{l}\text { Mark learning outcomes related to "Technical } \\
\text { documentation" that have been enhanced during } \\
\text { your experience: }\end{array}$} & $\begin{array}{c}\text { NAAB } \\
2014\end{array}$ & $\begin{array}{c}\text { UIA } \\
2017\end{array}$ & $\begin{array}{c}\text { RIBA } \\
2014\end{array}$ \\
\hline$\square$ & $\begin{array}{l}\text { Awareness of the role of technical documentation } \\
\text { and specifications in design realization. }\end{array}$ & & 4.2.4. & \\
\hline$\square$ & $\begin{array}{l}\text { Awareness of the processes of construction, cost, } \\
\text { planning and control. }\end{array}$ & & 4.2.4. & \\
\hline$\square$ & Ability to make technically clear drawings. & B.4 & & \\
\hline$\square$ & Ability to prepare outline specifications & B.4 & & \\
\hline$\square$ & $\begin{array}{l}\text { Ability to construct models illustrating and } \\
\text { identifying the assembly of materials, systems, and } \\
\text { components appropriate for a building design. }\end{array}$ & B.4 & & \\
\hline$\square$ & None of the above. & & & \\
\hline
\end{tabular}

\subsection{Sample selection}

Sixty students from each group were randomly selected and were invited to participate through private messages on Facebook. 28 students (46.7\%) from the Revit group responded, and 26 students (43.3\%) from the physical mock-up group responded. Although the sample of the physical mock-up experience was randomly selected, it was considered that close numbers of its 9 groups were involved in the study.

\section{RESULTS AND DISCUSSION}

The following is a description of the sample: $21.4 \%(\mathrm{~N}=6)$ of the Revit group were males, while $34.6 \%(\mathrm{~N}=9)$ of the mock-up group were males. Respondents could choose more than one field of current work. $25 \%(\mathrm{~N}=7)$ of the Revit group currently practice execution design in office, and $14.3 \%(\mathrm{~N}=4)$ work on site. While $38.5 \%(\mathrm{~N}=10)$ of the mock-up group currently practice execution design in office, and $11.5 \%(\mathrm{~N}=3)$ work on site. The average rating for respondents' satisfaction of their experience was 3.89/5 for the Revit group and $4.04 / 5$ for the mock-up group.

Results and discussion will be presented, in two phases: The first phase presents the relevance of educational realms to each experience, while the second stage presents and discusses some detailed results and highlights related to learning outcomes. " $R$ " denotes the Revit experience, "M" denotes the physical mock-up experience, and "FT" denotes the $p$ value for Fisher's exact test. 


\subsection{Educational realms}

The first phase of analysing results looks at the percentage of respondents who did not mark "None of the above" for each educational realm (see Table 1). In another meaning, it looks for respondents who has chosen one or more of the learning outcomes for each educational realm. This percentage indicates the relevance of each educational realm to both experiences.

The Revit experience seems to be significantly more related to structural systems $(\mathrm{R}=89.3 \%, \mathrm{M}=65.4 \%, \mathrm{FT}=0.051)$; building envelopes and assemblies $(\mathrm{R}=67.9 \%, \mathrm{M}=34.6 \%$, $\mathrm{FT}=0.028)$; and building service systems $(\mathrm{R}=53.6 \%, \mathrm{M}=0.07 \%, \mathrm{FT}=0.000)$ comparing to the mock-up experience. While the mock-up experience seems to be significantly more related to financial considerations $(\mathrm{R}=28.6 \%, \mathrm{M}=92.3 \%, \mathrm{FT}=0.000)$; flexibility and adaptability $(\mathrm{R}=42.9 \%, \mathrm{M}=92.3 \%$, $\mathrm{FT}=0.000)$; collaboration skills $(\mathrm{R}=39.3 \%, \mathrm{M}=88.5 \%$, $\mathrm{FT}=0.000)$; project management $(\mathrm{R}=46.4 \%, \mathrm{M}=84.6 \%, \mathrm{FT}=0.005)$; time management $(\mathrm{R}=39.3 \%$, $\mathrm{M}=73.1 \%, \mathrm{FT}=0.016)$; and business practices $(\mathrm{R}=14.3 \%, \mathrm{M}=53.8 \%, \mathrm{FT}=0.003)$ comparing to the Revit experience.

The Revit experience slightly outperforms its counterpart in realms of integrative design $(\mathrm{R}=71.4 \%, \mathrm{M}=53.8 \%, \mathrm{FT}=0.260)$; metacognitive skills $(\mathrm{R}=82.1 \%, \mathrm{M}=61.5 \%, \mathrm{FT}=0.131)$; and stakeholder roles in architecture $(\mathrm{R}=75 \%, \mathrm{M}=57.7 \%, \mathrm{FT}=0.250)$. While the mock-up experience slightly outperforms its counterpart in realms of professional communication skills $(\mathrm{R}=89.3 \%, \mathrm{M}=100 \%, \mathrm{RT}=0.237)$; and codes and regulations related to design and construction $(\mathrm{R}=32.1 \%, \mathrm{M}=50 \%, \mathrm{FT}=0.268)$.

On the other hand, both experiences seem to enhance the following educational realms: technical documentation $(\mathrm{R}=100 \%, \mathrm{M}=100 \%, \mathrm{FT}=1.000)$; execution design thinking skills $(\mathrm{R}=96.4 \%, \mathrm{M}=100 \%, \mathrm{FT}=1.000)$; investigative skills $(\mathrm{R}=85.7 \%, \mathrm{M}=96.2 \%, \mathrm{RT}=0.353)$; building materials and assemblies $(\mathrm{R}=89.3 \%, \mathrm{M}=84.6 \%, \mathrm{FT}=0.700)$; research $(\mathrm{R}=85.7 \%$, $\mathrm{M}=88.5 \%, \mathrm{FT}=1.000)$; use of precedents $(\mathrm{R}=82.1 \%, \mathrm{M}=80.8 \%$, $\mathrm{RT}=1.000)$; ability to work autonomously and take responsibility $(\mathrm{R}=75 \%, \mathrm{M}=69.2 \%, \mathrm{RT}=0.764)$; integrated evaluations and decision-making design process $(\mathrm{R}=71.4 \%, \mathrm{M}=69.2 \%, \mathrm{FT}=1.000)$. While legal responsibilities $(\mathrm{R}=21.4 \%, \mathrm{M}=15.4 \%, \mathrm{FT}=0.730)$ and professional conduct $(\mathrm{R}=17.9 \%$, $\mathrm{M}=26.9 \%, \mathrm{FT}=0.520$ ) were weakly related to both experiences.

The results are in line with what was expected and what was found in the literature, except that the aspect of "codes and regulations related to design and execution" was not found to be relevant through the interviews nor through the literature review.

\subsection{Learning outcomes}

The second phase of analysing results takes a closer look for the learning outcomes that were enhanced within each educational realm through both experiences. The presentation will be in the order of the educational realms mentioned earlier as possible.

Regarding learning outcomes related to structure, the Revit group indicated better ability to demonstrate the basic principles of "structural systems" $(\mathrm{R}=71.4 \%, \mathrm{M}=50 \%, \mathrm{FT}=0.163)$ and better ability to select and apply appropriate structural systems $(\mathrm{R}=60.7 \%, 38.3 \%$, $\mathrm{FT}=0.173$ ). The different designs among students in the Revit experience required the students to select and apply the appropriate structural system for their own design. They were also able to do a simple analysis of the structural system. While one of the students of the mock-up group indicated that their experience influenced their understanding of the concept of "something carrying something else".

Regarding learning outcomes related to building envelopes and assemblies, the Revit group indicated better understanding of the basic principles for selection and application 
of building envelope systems $(\mathrm{R}=57.1 \%, \mathrm{M}=34.6 \%, \mathrm{FT}=0.111)$. The environmental performance of building envelopes was not studied. However, students had to manage water insulation, and some had dealt with heat insulation also.

Regarding learning outcomes related to building service systems, the Revit group significantly indicated better understanding of the basic principles and appropriate application of building service systems $(\mathrm{R}=57.1 \%, \mathrm{M}=7.7 \%, \mathrm{FT}=0.000)$. The Revit group stated that they had slightly dealt with MEP systems, which were not previously addressed through their academic study at the time.

Regarding learning outcomes related to financial considerations, the mock-up group significantly indicated better understanding of cost control mechanisms $(\mathrm{R}=3.6 \%, \mathrm{M}=73.1 \%$, $\mathrm{FT}=0.000$ ) and better examination of financial factors implied in varying building types and systems $(\mathrm{R}=25 \%, \mathrm{M}=61.5 \%, \mathrm{FT}=0.013)$. The mock-up project was funded by students themselves. They were responsible for the procurement of materials and the provision of the necessary tools.

The mock-up group significantly indicated better flexibility and adaptability ( $\mathrm{R}=42.9 \%$, $\mathrm{M}=92.3 \%, \mathrm{FT}=0.000)$; better time management $(\mathrm{R}=39.3 \%, \mathrm{M}=73.1 \%, \mathrm{FT}=0.016)$; and better ability to work in collaboration with other members $(\mathrm{R}=39.3 \%, \mathrm{M}=88.5 \%, \mathrm{FT}=0.000)$. Many of the mock-up group indicated that they had faced several challenges such as time, managing execution and dealing with team members who were sometimes hard to handle.

Regarding learning outcomes related to project management, the mock-up group significantly indicated better ability to identify work plans, project schedules and time requirements $(\mathrm{R}=32.1 \%, \mathrm{M}=84.6 \%, \mathrm{FT}=0.000)$. Also, the mock-up group significantly indicated better awareness of methods for selecting consultants and assembling teams $(\mathrm{R}=14.3 \%, \mathrm{M}=46.2 \%, \mathrm{FT}=0.017)$. Some of the mock-up groups went to several wood workshops in order to get the best prices. Others contracted carpenters to prepare specific pieces that they designed for their project such as the parquet group.

Regarding learning outcomes related to business practices, the mock-up group significantly indicated better understanding of the basic principles of the firm's business practices including financial management and business planning $(\mathrm{R}=10.7 \%, \mathrm{M}=38.5 \%, \mathrm{FT}=0.026)$.

Regarding learning outcomes related to integrative design, both groups indicated enhancement in integrating and considering technical documentation, site conditions, environmental systems, structural systems, and building envelopes systems and assemblies. But the Revit experience had a bit greater impact $(\mathrm{R}=71.4 \%, \mathrm{M}=53.8 \%, \mathrm{FT}=0.26)$. The Revit group students had to integrate structural system, building envelope, openings, and finishing, etc. to form one whole model for the building. On the other hand, the mock-up group students had to integrate the parts (that each group had implemented) together to form the whole project. In both cases students became more aware of the elements that they had to consider during the design process.

Regarding learning outcomes related to metacognitive skills, both groups indicated that their experiences enhanced their ability to identify one's learning needs. But the Revit experience had a bit greater impact on this due to its entire reliance on autonomous work $(\mathrm{R}=82.1 \%, \mathrm{M}=61.5 \%, \mathrm{FT}=0.131)$.

Regarding learning outcomes related to stakeholder roles, both groups indicated that their experiences enhanced their understanding of the potential roles of architects $(\mathrm{R}=53.6 \%$, $\mathrm{M}=50 \%, \mathrm{FT}=1.000$ ). Students of the mock-up group discovered new aspects of dealing with craftsmen, managing costs, and other matters of execution processes that they do not usually encounter in the construction studio. While it is not clear why this learning outcome improved for the Revit group. Also, the Revit group indicated a bit better understanding of the architect's role to reconcile stakeholder needs $(\mathrm{R}=50 \%, \mathrm{M}=34.6 \%, \mathrm{FT}=0.284)$. Students of 
the Revit group became aware of the multiplicity of systems and the importance of having specialists for each system to achieve integrative design.

Regarding learning outcomes related to professional communication skills, both groups indicated that their experiences enhanced their ability to use representational media each on its own way $(\mathrm{R}=82.1 \%, 84.6 \%, \mathrm{FT}=1.000)$. Both groups also indicated that their experiences enhanced their ability to communicate effectively through presentation, confirmation questions and note taking $(\mathrm{R}=46.4 \%, \mathrm{M}=53.8 \%, \mathrm{FT}=0.786)$. However, the mock-up group significantly indicated better awareness of the principles of negotiation $(\mathrm{R}=10 \%, \mathrm{M}=71.4 \%$, $\mathrm{FT}=0.000)$. They also indicated better ability to speak effectively $(\mathrm{R}=28.6 \%, \mathrm{M}=61.5 \%$, $\mathrm{FT}=0.028$ ). This is due to the teamwork framework of the Mock-up experience, and the negotiations with carpenters and sellers as well.

Regarding learning outcomes related to technical documentation, the Revit group indicated a bit better ability to construct models illustrating and identifying the assembly of materials, systems, and components appropriate for the building design ( $\mathrm{R}=92.9 \%$, $\mathrm{M}=71.4 \%, \mathrm{FT}=0.135)$. It also indicated a bit better ability to make technically clear drawings $(\mathrm{R}=85.7 \%, \mathrm{M}=73.1 \%, \mathrm{FT}=0.320)$. On the other hand, the mock-up group significantly indicated better awareness of the processes of construction, cost, planning and control $(\mathrm{R}=35.7 \%, \mathrm{M}=76.9 \%, \mathrm{FT}=0.003)$. This is due to the chronological nature of the events and processes that occurred in the mock-up experience.

Regarding learning outcomes related to execution design thinking skills, both groups indicated that their experiences enhanced their ability to: think three-dimensionally in the exploration of design ( $\mathrm{R}=92.9 \%, \mathrm{M}=84.6 \%, \mathrm{FT}=0.413)$; ability to raise clear and precise questions and define problems $(\mathrm{R}=75 \%, \mathrm{M}=69.2 \%, \mathrm{FT}=0.764)$; ability to test alternative outcomes against relevant criteria or standards $(\mathrm{R}=57.1 \%, \mathrm{M}=69.2 \%, \mathrm{FT}=0.408)$; ability to reach well-reasoned conclusions and critical judgement $(\mathrm{R}=67.9 \%, \mathrm{M}=57.7 \%, \mathrm{FT}=0.574)$; ability to gather information and use abstract ideas $(\mathrm{R}=39.3 \%, \mathrm{M}=50 \%, \mathrm{FT}=0.584)$; and ability to interpret information, apply analysis and critical judgement $(\mathrm{R}=35.7 \%, \mathrm{M}=46.2 \%$, 0.580 ). The mock-up group indicated a bit better ability to formulate strategies for action $(\mathrm{R}=53.6 \%, \mathrm{M}=73.1 \%, \mathrm{FT}=0.167)$. Also, the Mock-up group significantly indicated better ability to consider diverse points of view $(\mathrm{R}=53.6 \%, \mathrm{M}=84.6 \%, \mathrm{FT}=0.020)$; and ability to engage imagination and think creatively $(\mathrm{R}=39.3 \%, \mathrm{M}=69.2 \%, \mathrm{FT}=0.033)$.

The teamwork setting of the mock-up experience allowed various perspectives to be presented and various proposals to be tested, and strategies for organizing work among group members had emerged. In the Revit experience, views and solutions were limited to the opinion of the student, the tutor, and the professor. The strategy for organizing one's work in the Revit experience was less complicated because it was totally in an individual setting. Also, respondents of the mock-up group indicated that they were highly motivated to do whatever it takes to bring their project to life. This motivation had fuelled their ability to engage imagination and think creatively, and to gather information.

Regarding learning outcomes related to building materials and assemblies, both groups indicated that their experiences enhanced their understanding of the alternative materials that apply to architectural design and building construction $(\mathrm{R}=67.9 \%, \mathrm{M}=53.8 \%, \mathrm{FT}=0.403)$. The mock-up group indicated a bit better ability to evaluate materials, processes and techniques that apply to complex architectural designs and building construction, and to integrate these into execution design proposals $(\mathrm{R}=35.7 \%, \mathrm{M}=53.8 \%, \mathrm{FT}=0.273)$. The use of limited materials - such as wood - in the mock-up experience allowed the creation of a deep and detailed understanding of these specific materials in the student's mental library. While the diversity of materials that a student can explore through the Revit tool without any real restrictions in use (such as cost, transportation and installation issues), allows the student to 
gain a more comprehensive understanding. However, some of the Revit group respondents indicated that they were having some difficulty in modelling and applying materials that suit their designs due to their lack of experience in using the software.

Regarding learning outcomes related to research, both groups indicated that their experiences enhanced their critical understanding of how knowledge is advanced through research to produce clear, logically argued and original work relating to execution design $(\mathrm{R}=64.3 \%, \mathrm{M}=71.4 \%, \mathrm{FT}=0.379)$. Both experiences also enhanced respondents' understanding of the theoretical and applied research methodologies and practices used during the execution design process $(\mathrm{R}=53.6 \%, \mathrm{M}=61.5 \%, \mathrm{FT}=0.593)$. However, the scope of the research in the Revit experience has often been about "parts and connections", while the scope in mock-up experience has often been about "implementation of parts and connections".

Regarding learning outcomes related to use of precedents, both groups indicated that their experiences enhanced their ability to examine and comprehend the fundamental principles present in relevant precedents $(\mathrm{R}=71.4 \%, \mathrm{M}=65.4 \%, \mathrm{FT}=0.771)$. The Revit group significantly indicated better ability to make informed choices about the incorporation of precedents into projects $(\mathrm{R}=75 \%, \mathrm{M}=46.2 \%, \mathrm{FT}=0.050)$. This may have a direct relationship to the scale of the Revit project and the multiplicity of details and systems that the student needs to incorporate from precedents.

Both groups indicated that their experiences enhanced their ability to work autonomously and take responsibility within a practice context $(\mathrm{R}=75 \%, \mathrm{M}=69.2 \%, \mathrm{FT}=0.764)$. Even through the teamwork setting of the mock-up experience, most students indicated that assignments and responsibilities were distributed among them. Regarding learning outcomes related to integrated evaluations and decision-making design processes, both groups indicated that their experiences enhanced their ability to identify problems across multiple systems and variables $(\mathrm{R}=53.6 \%, \mathrm{M}=53.8 \%, \mathrm{FT}=1.000)$.

\section{LIMITATIONS AND FUTURE RESEARCH}

Like any research, this research has its limitations. Student assessment is fully subjective as it relies on their perception for their learning as opposed to using an objective measure of each of the learning outcomes. Student perceptions of learning may be influenced by a variety of other factors which were not measured or controlled in this study such as the experience of the faculty members, and students' learning styles.

Additionally, this study includes only a limited number of students enrolled in 2nd year construction course at the same university. Collecting data from a larger number of respondents from different institutions may be useful to provide a more complete picture of the performance of sophomore students. Additionally, there are other potentials for both tools that were not covered since students were from early stages of education. For example, the ability of Revit to analyse the environmental and structural performance of the building, was expected to be one of the most prominent strengths of using digital modelling. Thus, it would be beneficial to repeat this study with junior and senior students.

\section{CONCLUSION AND RECOMMENDATIONS}

Learning outcomes related to project-based learning within building construction courses can be enhanced through the use of different tools or "doing devices", such as digital modelling and physical modelling. Knowing the potential of each tool and its limitations will help educators make better decisions according to their educational goals. Some of the previous experiences and limitations associated with each tool have been reviewed through the literature. Then, a case study of Alexandria University aimed to explore the potentials of each tool to cover educational realms related to building construction courses, and the relative 
ability between the two tools to enhance learning outcomes. Creating a comprehensive list of learning outcomes related to building construction helped provide a rich and broad scope for testing. The literature review and the case study revealed the following:

- Both digital and physical modelling have good potentials to cover a wide range of educational realms and learning outcomes related to building construction.

- Digital modelling gives an opportunity to break through any constraints associated with project scale, materials, and costs.

- Digital modelling may require prerequisites to use the software. It is also important to know the educational background of the students to anticipate the extent to which the capabilities of the used program will be utilized.

- Unlike digital modelling, physical modelling helps to learn the processes involved in the execution and not just the materials and constituent elements.

- Physical modelling confronts the student with challenges related to site and implementation such as managing costs, time, materials and construction tools. Whereas students are less involved in these issues when using digital modelling.

- Physical modelling has limitations and challenges related to the location that will contain the model, costs and transportation methods of materials and systems. These challenges directly affect the type of projects that are compatible with using this tool according to the available capabilities.

- Regardless of the tool used, working in a teamwork and collaborative setting significantly enhances learning outcomes. It enhances students' ability to work in collaboration with other architects and members of interdisciplinary teams. It encourages students to consider diverse points of views. And it enhances their flexibility and adaptability.

- Regardless of the tool used, the scope of the project, the variety of its details and the complexity of its systems determine whether the learning outcomes related to the knowledge and technical skills are comprehensive, or deep and specific.

Finally, it is important for the educator to consider all the aforementioned aspects when choosing the "doing device" of the building construction project.

\section{ACKNOWLEDGEMENTS}

The authors acknowledge that they have no known competing financial interests or personal relationships that could have appeared to influence the work reported in this paper.

\section{REFERENCES}

[1] The National Architectural Accrediting Board (NAAB), 2014 conditions for accreditation, pp. 1-30, 2014.

[2] UNESCO-UIA VCAE, UNESCO-UIA charter for architectural education, pp. 1-12, 2017.

[3] RIBA, RIBA procedures for validation and validation criteria for UK and international courses and examinations in architecture, pp. 1-72, 2014.

[4] Schank, R.C., What we learn when we learn by doing. Institute for the Learning Sciences, Northwestern University, Report No. 60, 1995.

[5] Emami, N. \& Buelow, P.V., Teaching structures to architecture students through hands-on activities. Presented at: Canadian International Conference on Advances in Education, Teaching, and Technology, 2016. 
[6] Sun, L., Fukuda, T., Tokuhara, T. \& Yabuki, N., Differences in spatial understanding between physical and virtual models. Frontiers of Architectural Research, 3, pp. 2835, 2014.

[7] Abdelhady, O. \& Farid, M.M.A., Assessing the impact of architectural physical models in architectural design education. DAKAM's International Journal of Architecture and Urban, 2018.

[8] Yang, P., Humanities education reform exploration and practice under outcomes-based education (OBE). Obrazovanie i Nauka, 22, pp. 78-97, 2020.

[9] Folić, B., Kosanović, S., Glažar, T. \& Fikfak, A., Design-build concept in architectural education. Architecture and Urban Planning, 11, pp. 49-55, 2016.

[10] Garnjost, P. \& Lawter, L., Undergraduates' satisfaction and perceptions of learning outcomes across teacher- and learner-focused pedagogies. International Journal of Management Education, 17, pp. 267-275, 2019.

[11] Prince, M. \& Felder, R., The many faces of inductive teaching and learning. Journal of College Science Teaching, 36, pp. 14-20, 2007.

[12] Oguz-Unver, A. \& Arabacioglu, S., A comparison of inquiry-based learning (IBL), problem-based learning (PBL) and project-based learning (PJBL). Academia Journal of Educational Research, 2, pp. 120-128, 2014.

[13] Tang, L., Jin, R. \& Fang, K., Launching the innovative BIM module for the architecture and built environment programme in China. Building Information Modelling (BIM) in Design, Construction and Operations, pp. 145-156, 2015.

[14] Lim, Y.W., Building information modeling for indoor environmental performance analysis. American Journal of Environmental Sciences, 11, pp. 55-61, 2015.

[15] Nawari, N.O., Studying architectural structures using BIM tools. Journal of Civil Engineering and Science, 2, pp. 37-47, 2013.

[16] Hazzan, O., Pikas, E. \& Sacks, R., Building Information Modeling education for construction engineering and management. II: Procedures and implementation case study. Journal of Construction Engineering and Management, pp. 1-13, 2013.

[17] Lassen, A.K., Hjelseth, E. \& Tollnes, T., Enhancing learning outcomes by introducing bim in civil engineering studies - experiences from a university college in Norway. International Journal of Sustainable Development and Planning, 13, pp. 62-72, 2018.

[18] Carpenter, W.J., Learning by Building: Design and Construction in Architectural Education, Van Nostrand Reinhold: New York, 1997.

[19] Wallis, L., Building the studio environment. Design Studio Pedagogy: Horizons for the Future, eds A.M.A. Salama \& N. Wilkinson, Urban International Press: Gateshead, pp. 201-218, 2007.

[20] Limbuddha-augsorn, S. \& Sahachaisaree, N., An analysis of mockup cost effectiveness to verify the accuracy of stimuli approach: A case study of interior design for VIP inpatient rooms (single). Procedia - Social and Behavioral Sciences, 5, pp. 1251-1256, 2010.

[21] Schwartz, C., Debating the merits of design/build: Assessing pedagogical strategies in an architectural technology course. Journal of Applied Sciences and Arts, 1, p. 2, 2015.

[22] Gaber, T., The agency of making and architecture education: Design-build curriculum in a new school of architecture. International Journal of Architectural Research, 8, pp. 21-31, 2014.

[23] Canizaro, V.B., Design-build in architectural education: Motivations, practices, challenges, successes and failures. International Journal of Architectural Research, 6(1), pp. 20-36, 2012. 
[24] Schreyer, A.C., 3D modeling and virtual mockup building as teaching tools in AEC materials and methods curricula. ASC 50th Annual International Conference, pp. 1-9, 2014.

[25] Melcher, K., Leaving the Drafting Table: Students' Perspectives on the Design-Build Experience, Landscape Research Record, 2013. 